Les Cahiers d'Afrique de l'Est / The East

African Review

46-2 | 2013

Orphelins, enfants vulnérables et jeunesse violente

\title{
Youth and Elders: The Way Out after the Crisis in Burundi
}

\section{Christian Thibon}

\section{(2) OpenEdition \\ 12 Journals}

\section{Electronic version}

URL: https://journals.openedition.org/eastafrica/423

DOI: 10.4000 /eastafrica.423

ISSN: 2790-1076

\section{Publisher}

IFRA - Institut Français de Recherche en Afrique

\section{Printed version}

Date of publication: 1 January 2013

Number of pages: 105-113

ISSN: 2071-7245

\section{Electronic reference}

Christian Thibon, "Youth and Elders: The Way Out after the Crisis in Burundi", Les Cahiers d'Afrique de I'Est / The East African Review [Online], 46-2 | 2013, Online since 07 May 2019, connection on 09 December 2021. URL: http://journals.openedition.org/eastafrica/423 ; DOI: https://doi.org/10.4000/ eastafrica. 423

This text was automatically generated on 9 December 2021.

Les Cahiers d'Afrique de l'Est / The East African Review 


\title{
Youth and Elders: The Way Out after the Crisis in Burundi
}

\author{
Christian Thibon
}

1 During the war (1993-2005), whether it was settled in the urban areas of Bujumbura or in rural areas, the Burundian population ${ }^{1}$ has encountered extreme situations, family dramas, disappearances, uprooting and forced displacements within their families and households. With the return of peace and a way out of the crisis, the challenges of the reconstruction are increasing and accumulating without solutions some of the population's problems (unemployment, public health...). Moreover the household changes are striking, in particular regarding the binomial relationship between elders and young adults, the relations within families and households and the role and status given to the youth and to women. The analysis will look particularly at the changes experienced by the youth, their status and role, and both domestic and social tensions. It will include their implications in the political sphere. In conclusion, this article will question how old and new tensions within families are regulated, absorbed and if or how they are on the way to resilience.

2 This paper presents some results of a research in demography and political science that deals with new habits and practices of the youth within families and households and, in a broader scale, in the society through political mobilization, deviant and sometimes violent or perceived violent behaviours. This research tackles the classical questions of modernisation of family relations and violence in politics. The connecting thread is the perspective and the historical reconstitution that will help to understand the importance of the current changes but also of the weight of family patterns and inherited representations. Eventually, this article will explore the gap existing between real situations and family values: for this reason, the research will analyse the historical situations in three time periods, pre-colonial, colonial and post-colonial, and the current period since the 1993 social political crisis followed by civil war (1993-2005).

3 The youth in Burundi have been the subject of few researches mainly in the 1970s-80s and only in specific areas. ${ }^{2}$ On the one hand childhood ages have been studied in 
relation to schooling supply related to educational and psycho-educational reflection. On the other hand, the question of the younger generation within the society, the unmarried dependants as a social emerging group or class have created a historiographical debate, ${ }^{3}$ mostly because this question was not seen as topical or as a priority. Besides, regarding the extensive ethnographic literature on such a subject in the neighbouring East African countries, this disinterest might result from what seems to be an anthropological anomaly compared to neighbouring situations: the quasimissing instituted young age class in Burundi. In reality, this situation is more a paradox as the societal roles of young men "umisore" and young women "inkumi" (age from puberty to late marriage) are important. However their assigned place, their status and therefore the recognition of this age are weak. Indeed traditionally, unmarried young people stay "children," even though some terms give youth a generational specificity and attribute to them functions and activities. These attributions are limited to the aristocracy and the court society. It is what A. Kagame ${ }^{5}$ underlined in the case of Rwanda and that is found in some functions occupied by boys and girls at the king, princes and chiefs' courts in Burundi.

\section{Elders and young people in the "traditional" pre- colonial society}

During pre-colonial times, the economic, social and political importance of the young people, the "demographic youth," through social practices, cultural traits and initiation rituals was not associated with social recognition. The pressure on young people was to get married and therefore their place in society and their number were essential to the group's reproduction. This political and domestic reproduction was capital for the power of the chief (chiefs, princes and King), for the survival of the family farm, as well as for the prestige and honour of the chief and his rugo and household. Thus, at the turn of the $19^{\text {th }}-20^{\text {th }}$ century, from the Court to the rugo, from royal and princely capitals to the family farm, the tasks attributed to young men were vital. Indeed they were in charge of herd keeping and maintenance especially at the time of cattle migration, agricultural land clearing, defence groups and war mobilisation, and in periods of food shortage or famine they were in charge of finding food. Young women were in charge of important tasks as well: farming and domestic activities. The large number of young people testifies to the wealth and good fortune of chiefs, politicians, rugo and household chiefs. In this context, they have great interest in delaying the age of marriage of their descendants. This situation characterises the ancient demographic profile and a large household family model, constituent of the family culture that has lasted throughout the $20^{\text {th }}$ century. However it has been weakened partly by rare resources and densely populated spaces and has lead to power struggles that remain because of the low technical level reached in the farming as well as in the war sectors. The only asset capitalizable, apart from cows, is young people who are their descendants. There are two kinds of domestic accumulation: on the one hand high fertility contributes greatly to it and on the other hand the court social attraction, the creation of dependency as regarded the youth, the sharecropping to the domestic dependants and the bashumba are other ways to capitalize youths.

There are several possible reasons why there has been this capitalization of young people. First it could be a regulating mechanism, imposed on a population and 
associated with high density in closed rural areas that have encountered crisis, which was the case at the turn of the $19^{\text {th }}-20^{\text {th }}$ century and $21^{\text {st }}$ century. Secondly, it could result from a managing strategy of asset accumulation in the hands of the elders and household heads wanting to reach the models of the "great chief" or the "great family." Most probably these two reasons, demo-economic determinism and the reproduction of models-strategies, intervene to capitalize the largest number of descendants, but also the most matrimonial relations-alliances, business partnerships and dependants possible. In these conditions, the imposed or desired late marriage, the controlled delay of marriage by the household elders-chiefs, more generally the matrimonial strategies and the inheritance strategies automatically create, in demographical terms, an important age group. However this age group has not been transformed into recognized and instituted categories, that is to say age group or practices, residual or not, associated with them like initiation and isolation rites, collective learning rites and reinsertion rites, of which we can only find residual testimony. ${ }^{7}$

6 This situation could be explosive at the household level because of the relationship between young adults and married adults, as well as at the social level through the increasing number of family dependants and domestic dependants (the bashumba assimilated to children). This has given rise to some protesting mobilizations (like the case of the anti-king and the rebellions at the turn of the $19^{\text {th }}-20^{\text {th }}$ century), but this is yet to be verified. But the ascendancy of the elders, who are the household heads, on the young adults is idealized in the family and social values that are authoritative, very prescriptive and unequal. The moral education is actually a hard training through rules of distance and prescription on sexuality that are experimented on and reinforced daily in the co-residence of the households under the patriarchal authority within the ingo (kind of scattered houses that belong to one household gathered in a closed area), in the matrimonial practices (alliance choices imposed by the elders), and in the inheritance customaries (the pre-eminence of the elder brother). Any young people that do not follow these norms and social conformity are subjected to either a social and sometimes physical death: the repudiation or exclusion for the young man and the death for a daughter or a mother. However this family system, at least in the familial patriarchal model, is in reality more flexible. The symbolic violence that it generates has been subjected to several modifications: to the protection that the elders give to the young adults, practices have been put in place allowing young men compensation. These include: access to land in order to constitute the dowry (land gift is called icibare), access to women (sexual freedom is tolerated for young men) and the possibility of establishing a household within the common part of the family land in the form of huts settled in clusters. Indeed land margins exist and allow the family's younger sons to settle close to their father's rugo. Lastly, there is also another individual way out of the hierarchal or social dependency: a young man has the possibility to change his father from a biological elder to a social elder.

7 During colonialization economic, social and cultural changes brought change in the above described model or system without necessarily questioning it. 


\section{Elders and youth during the colonial and post-colonial period: the predominance of a family model confronted to an eroded family system}

Like in the pre-colonial period, the age of marriage is an important key to understand societal evolutions; at that time the age of marriage is more known and better measured. Thus, the age of marriage has encountered a differentiated evolution, which is concealed by stable general averages: according to the regions, it has been observed that the age of marriage has been brought down or that it has reached an upper limit.

On the one hand, there has been questioning of the elders authority through the occurrence of "seduction kidnapping," which consists of a marriage imposed by the young adults on the elders. This freedom that had worried the colonial jurisprudence and the Catholic Church is a consequence of a growing mobility of young people associated with the colonial market economy. Indeed the seasonal income from the plantation economy and international migrations had freed the young people from the elders. Also, more and more monetary, the constitution of dowry depended less on the family contribution and allowed young people to access marriage earlier. On the other hand, the authoritarian strategies of the large family model took advantage of the academic success of their descendants and of the agricultural land expansion, thanks to a plantation economy, that validated the accumulation of people able to work within the family. In these two cases that suggested two regional family evolutions, land and economical margins but also the dependency patterns (pastoral clientelism, sharecropping...) allowed internal regulation.

The Catholic Church diagnosed in the 1950s a double evolution of customs: if it worried about the rise of individualism and modernisation out of tradition, it praised the rural family values, a modernisation within the tradition or a "moral order of the high lands" following A. Guichaoua's expression. The Christian moralisation then grounded itself in the authoritarian traditional values.

11 From Independence to the 1990s, the system described above was eroded because the ways tensions were regulated between elders and youth had been exhausted; family resilience and household reproduction became more and more difficult, but the family model remained the reference.

12 Firstly, for a demographic reason: the family system experienced limits following the spectacular growth of the 15 to 25 year age group. Secondly there were economic reasons including the depletion of land margins from the 1980s, the national borders closing during the Independence that annihilated possible circular migrations, not really compensated by the limited urbanisation, and then the exhaustion of the essentially public employment market because of the structural adjustment plans from the 1990s. Lastly, there were social reasons because the dependency model (pastoral and land clientelism) was contested, then abolished.

In such a context only the access to formal employment, that is to say mainly in education and civil services, could give a margin for the reproduction of the large family model to some households that maintained their agro-pastoral assets and who benefited from the intergenerational transfers from the city to the rural areas, from the promoted young adults to the rural parents. 

increasing power of the youth, which, manipulated or not, occupies political and military ground. This mobilisation of young people is fed by radicalisation and appears in two ways across ethnic divisions. The mobilisation takes the shape of urban Tutsi militias, manipulated by politicians and radical minority political parties worried about participating in the political atmosphere and its diverse haggling between the score of armed groups that control the capital. However, as the power split itself, the risk a "Somali" drift between 1994 and 1998 appeared when in a country at civil war, the militias, arisen from pre-crisis urban youth groups, over flanked the elders, escaping their control and radicalizing the string of events. The coup d'État by P. Buyoya in 1997 that illustrated the return to power of the former single-party and the army, also marked the control over the young Tutsis militiamen in two ways: their encampment, 
at least their control-insertion in the para-military movement of the "Patriots" and their engagement in the Congo wars outside and far from Burundi. The mobilisation of the young Hutus followed another route. They were part of different Hutu armed rebellions, including the CNDD-FDD (Conseil National pour la Défense de la Démocratie, Forces de Défense de la Démocratie). This politico-military party capitalized on the best of the war generation of young promoted and blocked Hutus, from the refugees and IDPs' camps, which brought this party to power thanks to military and even more political victories. In 2005, the CNDD-FDD won the elections and seduced a part of the young Tutsi voters. This politico-military victory gave to the militants from the resistance movement the status of "umugabo" traditionally given to warriors and married men. Symptomatically, a debate took place on the distinction between "umugabo" to which the young CNDD-FDD militant-militiamen identified themselves because they came to power but were not necessarily married, and the "mushingatahe" by definition the wise man, the elder to which the militants from the ex-single-party, the UPRONA (Union pour le PRogrés NAtional), identified themselves.

As usual at the time of change of the political group in power, even if the youth supported the renewal of the political elites by a new generation of leaders coming from the rebellion, they did not get the expected benefits out of it. Either the young people were confined to the youth movements of the party, as it used to be in the past, and were in charge of the political and often violent actions ${ }^{8}$; or they were frustrated by a reconstruction that did not take into account their interests and ideals, and therefore they carried over their preferences on new parties formed during the rebellion or the urban contestation, as it was the case in the $2010^{9}$ elections. During the last elections, different from the 1960-1990s and because the political system opening to the civil society was regulated by election days and cyclical mobilizations, the youth have become a key stakeholder in the political life thanks to their presence and polling force. This emergence is all the stronger, like said in N. Hajayandi's ${ }^{10} \mathrm{PhD}$ Thesis on young people socialization, because it is happening in a context of generational division with the traditional and institutional frameworks including the State, school, established churches and the family in crisis.

This new political order is rooted in socio-anthropological changes and reflects them partly. These tendencies appeared in the 1980s but their traits have been accentuated by the effects of the crisis, the civil war and the post-crisis periods. This new context results in, on one hand, tensions that weighed on the youth, on the other hand, behaviours and deviant practices that suggested, beyond the downfall of households, a critic of the dominant model coming from the young people and after all the difficulty of a resilience for a large minority of households. Paradoxically, the " traditional " family model continues to capitalize young people without ensuring its redistribution function for the majority of households and families.

This new demographic environment and its new trends remain to be specified. The demographic facts collected during the last demographic surveys (DHS 2007, urban survey 2005-07, ESDR 2002) and the last general population census in 2008 (data volume III analysis April 2011, Interior Minister, Census Bureau), put in a historical perspective for some of them, ${ }^{11}$ uncovered revealing structural changes of the new living conditions of young people.

23 All these indicators show an evolution of the matrimonial market with two complex developments. Firstly the matrimonial market tends to close up as indicated by the 
increase of the age for marriage. Also young people respond to such challenges by new practices including co-habitation that have strongly increased. Indeed, the delay to the entrance in co-habitation or marriage, ${ }^{12}$ already historically high, has increased, especially for men, accentuating the age gap in marriage between men and women. The average age of the first union has increased between 1999 and 2008 from 20.8 years to 22.5 years for women and 22.6 years to 24.7 years for men with important differences between rural and urban areas. In cities, the age of the first union is 25.1 years for women and 28.9 years for men; this age gap is increasing in cities and in the dynamic western provinces caused by the effect of male migrations. This unbalanced matrimonial market is not only due to mechanisms induced by migrations, but also results from competition for widowers, remarriages and the increase of polygamy of established household heads, mainly persons of private means according to the 2008 RGP. It is also quite difficult to constitute dowry and therefore it is unfavourable to young men who are waiting for marriage. Thus, these young men are placed in a position of an adult "child" because marriage means becoming an adult.

Amongst young people, there has been an increase of common-law unions. This evolution is observed more in the Northern densely populated rural provinces. However there is a high rate of common-law union break-ups. This situation reveals the instability of households but also freedom taken by young people from tradition, reminiscent of the "seduction kidnapping" condemned during the colonial period but nowadays accepted and imposed by the society. The liberal law in terms of house building ${ }^{13}$ allows this de facto common-law union practice that happens mostly in the deference of marriage which remains the main act of social recognition. The marriage committees are more and more composed of third-parties from the same generation, replacing the relatives who traditionally sat in these committees. This is a sign that the "modern family" ${ }^{14}$ model centred more on the couple than on the family alliances has developed recently. The crisis has weakened families, family relationships and households (due to the increasing of the nuclear family). Young people and to a lesser extent women have de facto acquired a new status that the tradition hasn't recognized yet, but contribute more and more to the household's income. A minority of women and young people have even become household heads and breadwinners. Even if these changes appear mainly in the lower social classes and poor areas, and therefore might be more imposed than chosen, they still testify to the increase in power of the youth. Several other indicators tend to confirm this trend: intermediary variables (early sexual behaviour, family planning demand, individual international migration strategies), new collective social practices in the search for new communities "muryango," new dreams and eventually individual practices (youth and women religious mobility toward new religions and churches: Adventist, Pentecostal... ${ }^{15}$ splitting with the traditional norms and codes. A symptomatic phenomenon is the appearance, especially in towns, of the teenagers age group often displayed through appearances associated to the globalization and the international culture.

However this double movement of closing and opening, unfavourable and favourable to the young people, in a depressive economic context is conflicting because of the larger general context of Burundi: overpopulated rural areas, urban housing crisis, and having different generations live under one roof. Thus the co-habitation in the same household of the weakened family unit and the young adults is more and more frequent, while the community and family solidarity observed during the crisis is slowly replaced by a household withdrawal. ${ }^{16}$ This pressure results in an increase of 
domestic violence and judiciary disputes between parents and children, between brothers, relatives but also from victims who talk more easily when they are confronted with violence that traditionally were kept quiet. But, the " traditional " normative cultural models remain important. The reproduction of values remains the elders' job; even if they are criticized, they continue to serve as references of cultural and psychological recourses. But they do not have the capacity to maintain or the submission power they had in the past, because the majority of young people cannot access them or do not recognize themselves in them: this is the limit to resilience.

As always in Burundi this symbolic violence then finds its collective responses: a shortcut in identity divisions that can be reinforced by the frustration, all the more if politicians want to take advantage of this lack of recognition and this protesting impatience of the 15-25 year old people (1/4 of the Burundian population). There are also individual and collective responses that are in search of modernization, mobility and migration; a dynamic to which the public policy should respond.

\section{BIBLIOGRAPHY}

Botte, R. 1974. "Le processus de formation d'une classe sociale dans une société africaine précapitaliste." Cahiers d'études africaines 14: 605-626.

Manirakiza, R. 2008. Population et développement au Burundi, Paris: L'Harmattan.

Ngarambe, P., \& J.-L. Vinckle. 1981. "Pragmatique de la terminologie de la parenté rundi." In La Civilisation ancienne des peuples des Grands Lacs: 360-364. Paris: Karthala.

Ngayimpenda, E. 1999. “Crise socio-politique et déstructuration des ménages.” Cahiers démographiques du Burundi 13.

Nsabimana, T. 1993. “Le contrôle de la main-d'œuvre (fin XIX ${ }^{\mathrm{e}}$ - environ 1930)." Civilisations (mélange P. Salmon) 41: 307-327.

Ndimurukundo, N. 1981. "Les âges et les espaces de l'enfance dans le Burundi traditionnel." Journal des africanistes 51: 217-234.

Rutake, P. 1981. “Quelques aspects du droit coutumier." Droit et culture: 108-112.

Thibon, C. 2004. Histoire démographique du Burundi. Paris: Karthala.

\section{NOTES}

1. This research relies mainly on data from the urban survey implemented in 2005-07 in Bujumbura. The data is available online: villedebujumbura.org. The national data is from EDS-DHS and the general population census of 2008.

2. Ref. Bibliography.

3. Initiated by the work of R. Botte. 
4. Marriage and procreation for women determine the change into a man-head of household "umugabo" and a women-mother "umugore."

5. Ref. A. Kagame, 1959, La Notion de génération appliquée à la généalogie dynastique et à l'histoire du Rwanda. Brussels: Académie Royale des Sciences coloniales (ARSC), $117 \mathrm{p}$.

6. Traditional circular house with several huts, parent hut, son hut, domestic dependants hut, servant lull...

7. The case of the Rwandese itorero at the Rwandese court.

8. The youth movement of the single-party or of the party in power could be transformed in militias.

9. Including the support of the new parties, the FNL issued from the rebellion and the MSD issued from the urban civil society.

10. N. Hajayandi, The Political Socialisation of Youth in Burundi, PhD Thesis, Université de Pau-Pays de l'Adour, March 2011.

11. It is the case for basic demographic data (marriage age, fertility), it is less the case when taking into consideration new situations like common-law unions or the household structures measures.

12. The 2008 RGP take into consideration the age at the union which is different from the age of marriage.

13. P. Uvin, M. Sommers "Youth in Burundi and Rwanda, Contrasting Visions." In USIP, special report, 293, Oct 2011.

14. According to E. Shorter's expression.

15. C. Thibon "Religious Mobility in Burundi." In International Conference on Religious Mobility, CUEA/HIEDES/IFRA, April 2012.

16. This evolution is observed in the capital city Bujumbura and is still to be verified in the rural areas.

INDEX

Geographical index: Burundi 